\title{
Secondary Sjogren's Syndrome Presenting with Distal Tubular Acidosis and Quadriparesis
}

\author{
Kartik Munta, Manimala Rao Surath, K. Seshikiran \\ Department of Critical Care Medicine, Yashoda Multi-speciality Hospital, Hyderabad, Telangana, India
}

\section{Abstract}

A 52-year-old female patient was admitted to Intensive Care Unit with complaints of quadriparesis. Investigations revealed distal renal tubular acidosis (DRTA) secondary to Sjogren's syndrome with involvement of the parotid and thyroid glands. Laboratory investigations showed hyperchloremic metabolic acidosis and an alkaline urine $\mathrm{pH}$ with clinical signs of sicca syndrome. Sjogren's syndrome is associated with DRTA and occurrences of quadriparetic hypokalemia, nephrolithiasis, and osteomalacia can be prevented with early diagnosis and lifelong treatment with potassium and alkali replacement.

Keywords: Distal renal tubular acidosis, Hashimoto's thyroiditis, hypokalemia, Sjogren's syndrome

\section{INTRODUCTION}

Acute quadriparesis is seen commonly caused by severe hypokalemia. The cause of the severe hypokalemia usually may be drug induced, nutritional deficiency, or due to potassium wasting in renal tubular acidosis. The treatment involves correction of hypokalemia and diagnosing the precipitating causes of the hypokalemia. This case report intends to highlight the chances of an autoimmune disorder, such as Sjogren's syndrome as a causative etiology.

\section{Case Report}

A 52-year-old female was admitted with complaints of quadriparesis and slurring of speech for 2 days. She was a known hypertensive and was on treatment with beta-blockers. Her history was not suggestive of any medications or conditions which could have caused severe hypokalemia.

At presentation, she was normotensive with a heart rate of $60 / \mathrm{min}$ and electrocardiography changes suggestive of hypokalemia with U-waves [Figure 1]. Laboratory results showed severe hypokalemia $(1.5 \mathrm{meq} / \mathrm{L})$ and arterial blood gases revealed picture of metabolic acidosis with $\mathrm{pH} 7.22$ and serum bicarbonate $15.2 \mathrm{mmol} / \mathrm{L}$. Laboratory data showed serum chloride $111.3 \mathrm{meq} / \mathrm{L}$, magnesium $2.65 \mathrm{meq} / \mathrm{L}$, albumin 3.80, globulin 3.90, and an anion gap of 14. Further workup

\begin{tabular}{|l|l|}
\hline \multicolumn{3}{|c|}{ Access this article online } \\
\hline Quick Response Code: & Website: \\
\hline & www.ijccm.org \\
\cline { 2 - 2 } & \\
\hline
\end{tabular}

revealed urine $\mathrm{pH} 5.7$, a normal $24 \mathrm{~h}$ urinary potassium concentration of $40.36 \mathrm{mmol} /$ day, raised $24 \mathrm{~h}$ urinary calcium of $487 \mathrm{mg} /$ day, and normal serum cortisol.

Hypokalemia was corrected by potassium supplementation with monitoring of serum potassium 12 hourly. Thyroid profile showed hypothyroidism with elevated thyroid-stimulating hormone and thyroid antibodies level of $28.9 \mathrm{meq} / \mathrm{L}$, suggesting an autoimmune thyroid disorder.

An autoimmune antibody profile was sent to investigate the cause of distal renal tubular acidosis (DRTA) and it showed positive antinuclear antibody (ANA) of 1:80 and strong positive for SS-A, Ro-52 and mild positive for Ds-DNA. Further investigation into patient's history and clinical examination revealed complaints of dry eyes and mouth in the past and parotid swellings bilaterally. Biopsy of parotid could not be done due to refusal of consent by the patient. Based on the ANA profile, clinical history, parotid involvement, metabolic acidosis with severe hypokalemia, and autoimmune thyroiditis, a diagnosis of Sjogren's syndrome causing DRTA

Address for correspondence: Dr. Manimala Rao Surath, Department of Critical Care Medicine, Yashoda Multi-speciality Hospital, Somajiguda, Hyderabad - 500 082, Telangana, India. E-mail: manimalarao@hotmail.com

This is an open access article distributed under the terms of the Creative Commons Attribution-NonCommercial-ShareAlike 3.0 License, which allows others to remix, tweak, and build upon the work non-commercially, as long as the author is credited and the new creations are licensed under the identical terms.

For reprints contact: reprints@medknow.com

How to cite this article: Munta K, Surath MR, Seshikiran K. Secondary Sjogren's syndrome presenting with distal tubular acidosis and quadriparesis. Indian J Crit Care Med 2017;21:243-4. 


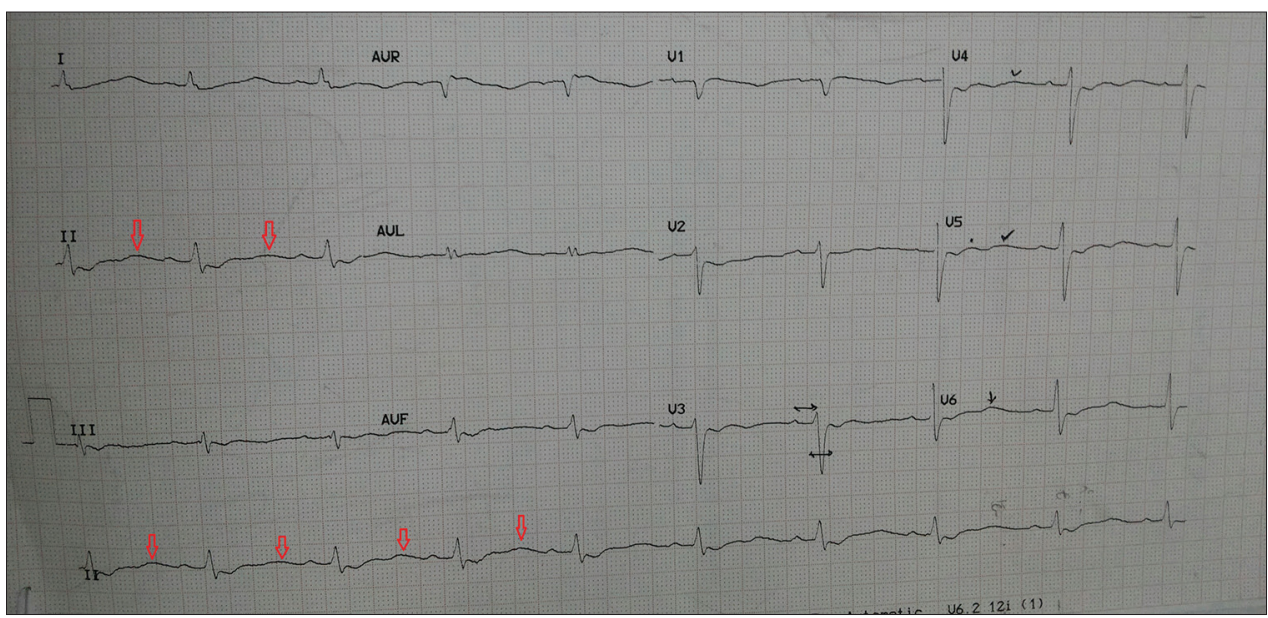

Figure 1: Electrocardiography showing characteristic U-waves seen in hypokalemia

with autoimmune thyroiditis was made. The patient responded well to the treatment with correction of potassium and supplementation of intravenous bicarbonate, showing marked improvement of weakness and speech.

\section{DISCUSSION}

Sjogren's syndrome is known to manifest through symptoms such as dry eyes and mouth. Renal involvement in Sjogren's syndrome is seen ranging from $4.2 \%$ to $50 \% \cdot{ }^{[1]}$ DRTA occurs due to an abnormality in renal acidification in the distal renal tubules, thereby leading to alkaline urine and hypokalemia. However, the occurrence of hypokalemic paralysis due to DRTA secondary to Sjogren's happens rarely.

Literature search has revealed only 18 cases between 1966 and 2004. ${ }^{[2]}$ The cause of DRTA in Sjogren's syndrome is not clearly understood. High levels of anticarbonic anhydrase antibodies affecting the functioning of carbonic anhydrase in collecting ducts and acidification defect due to lack of intact $\mathrm{H}+\mathrm{ATPase}$ pumps in intercalated cells have been found in such occurrences. ${ }^{[3,4]}$ Typically, patients present with hyperchloremia, metabolic acidosis, alkaline urine, renal hypercalciuria, and severe hypokalemia as it was seen in our case.

Secondary causes of DRTA include chronic active hepatitis, systemic lupus erythematosus, hypergammaglobulinemia, and Sjogren's syndrome. The autoimmune workup in our case revealed strong positive SSA and Ro-52 and mild positive Ds-DNA with clinical signs of parotid enlargement, xerostomia, and dry eyes which were helpful in diagnosing Sjogren's syndrome.

Sjogren's syndrome has been shown to occur more in the $40-45$ years age group with a female predominance of $10: 1 .^{[5]}$ The frequency of occurrence of Hashimoto's thyroiditis is higher in Sjogren's syndrome patients and is seen in 6.26\% as opposed to $1 \%-2 \%$ in normal population. In addition, $35 \%$ of thyroid disorder patients manifest sicca features making it difficult to determine whether a patient has primary Sjogren's syndrome or autoimmune thyroiditis. ${ }^{[6]}$

\section{Conclusion}

Patients presenting with severe hypokalemia causing muscular weakness should be worked up for a DRTA. This can be diagnosed with classic findings of metabolic acidosis, alkaline urine, normal anion gap, and positive urinary anion gap with hypokalemia.

While assessing for causes of DRTA occurrence in females of middle age, causative factors such as autoimmune disorders should also be investigated.

\section{Acknowledgments}

We gratefully acknowledge the management of the hospital for their valuable support.

\section{Financial support and sponsorship}

Nil.

\section{Conflicts of interest}

There are no conflicts of interest.

\section{RefEREnCES}

1. Bossini N, Savoldi S, Franceschini F, Mombelloni S, Baronio M, Cavazzana I, et al. Clinical and morphological features of kidney involvement in primary Sjögren's syndrome. Nephrol Dial Transplant 2001;16:2328-36

2. Soy M, Pamuk ON, Gerenli M, Celik Y. A primary Sjögren's syndrome patient with distal renal tubular acidosis, who presented with symptoms of hypokalemic periodic paralysis: Report of a case study and review of the literature. Rheumatol Int 2005;26:86-9.

3. Takemoto F, Hoshino J, Sawa N, Tamura Y, Tagami T, Yokota M, et al. Autoantibodies against carbonic anhydrase II are increased in renal tubular acidosis associated with Sjogren syndrome. Am J Med 2005;118:181-4.

4. Joo KW, Jeon US, Han JS, Ahn C, Kim S, Lee JS, et al. Absence of $\mathrm{H}(+)$-ATPase in the intercalated cells of renal tissues in classic distal renal tubular acidosis. Clin Nephrol 1998;49:226-31.

5. Pokorny G, Németh J, Marczinovits I, Kiss M, Hudák J, Husz S. Primary Sjögren's syndrome from the viewpoint of an internal physician. Int Ophthalmol 1991;15:401-6.

6. Zeher M, Horvath IF, Szanto A, Szodoray P. Autoimmune thyroid diseases in a large group of Hungarian patients with primary Sjögren's syndrome. Thyroid 2009;19:39-45. 